\title{
A Framework to Measure the Service Quality of Distributor with Fuzzy Graph Theoretic Approach
}

\author{
Tarun Kumar Gupta and Vikram Singh \\ Department of Mechanical Engineering, YMCA University of Science \& Technology, Faridabad, Haryana 121006, India \\ Correspondence should be addressed to Tarun Kumar Gupta; tarungupta1976@yahoo.com
}

Received 9 March 2016; Revised 20 June 2016; Accepted 27 July 2016

Academic Editor: Eleonora Bottani

Copyright ( 92016 T. K. Gupta and V. Singh. This is an open access article distributed under the Creative Commons Attribution License, which permits unrestricted use, distribution, and reproduction in any medium, provided the original work is properly cited.

\begin{abstract}
A combination of fuzzy logic and graph theoretic approach has been used to find the service quality of distributor in a manufacturing supply chain management. This combination is termed as the fuzzy graph theoretic (FGT) approach. Initially the identified factors were grouped by SPSS (statistical package for social science) software and then the digraph approach was applied. The interaction and inheritance values were calculated by fuzzy graph theory approach in terms of permanent function. Then a single numerical index was calculated by using permanent function which indicates the distributor service quality. This method can be used to compare the service quality of different distributors.
\end{abstract}

\section{Introduction}

Supply chain management (SCM) has gained much more attention for both academicians and practitioners for the past three decades. It is a big umbrella under which suppliers of supplier to end users are there. The main elements of SCM consist of a chain starting from the supplier to organization, distributor, retailer, and end user, that is, customer. As time to time checks and measures are necessary to maintain the efficiency and to increase motivation of every person or organization, the focus of recent study is to calculate the service quality of the distributor of a leading two wheeler manufacturing industry of North India, one of the most important element of SCM, who actually receives the product directly from the organization and supplies the same product to the retailers in small quantity as and when required. The distributor may be called an authorized stockiest who stores finish goods inventory because of trust, commitment, and market reputation of the parent organization and supplies the material to retailer according to demand [1]. In the current competitive world's business model, distributor is a key aspect and it is very important to choose the correct distributor for the business. Therefore a large number of studies have been conducted for the evaluation of distributors.
Initially, Shipley [2] evaluated the independent distributors based on the factors necessitating the application of effective selection and motivation criteria. Cavusgil et al. [3] developed a computer aided decision support tool for evaluating the foreign distributors. This tool provided the use of an interactive algorithm for arriving at reasonable conclusions. Sharma et al. [4] discussed a composite distributor performance index (DPI) to compare distributor's performance using a system dynamics approach. Lin and Chen [5] developed a research frame work to check the influence of various factors on distributor selection and evaluation. Chen and $\mathrm{Wu}[6]$ evaluated the relations of manufacturer and distributor by using ISM (Interpretive Structural Modeling), AHP (Analytical Hierarchy Process), and ANP (Analytic Network Process). ISM was used to sort system variables into groups of various characteristics and AHP and ANP to know the relative weightage of the variables. Ghorbani et al. [7] used Fuzzy ART (Adaptive Resonance Theory) for evaluating and ranking the 40 distributors.

Jonsson and Zineldin [8] indicated the necessity to build stable and long term working relationships between supplier and dealers and proposed a conceptual model including behavioral dimensions and found that good reputation and close and positive relationship are the main variables for 
TABLE 1: Demographic details of respondents.

\begin{tabular}{|c|c|c|c|c|c|c|c|c|c|}
\hline \multicolumn{2}{|c|}{ Age details } & \multicolumn{2}{|c|}{ Sex details } & \multicolumn{2}{|c|}{ Qualification details } & \multicolumn{2}{|c|}{ Echelon details } & \multicolumn{2}{|c|}{ Experience details } \\
\hline Age (years) & $\%$ age & Sex & $\%$ age & Qualification & $\%$ age & Echelon & $\%$ age & Exp. (years) & $\%$ age \\
\hline Up to 25 & 4.24 & Male & 79.66 & Technical & 72.03 & Organization & 50.85 & $1-5$ & 19.49 \\
\hline $25-30$ & 22.03 & Female & 20.34 & Nontechnical & 27.97 & Retailer & 49.15 & $6-10$ & 27.97 \\
\hline $30-35$ & 19.49 & & & & & & & $11-15$ & 23.73 \\
\hline $35-40$ & 25.42 & & & & & & & $16-20$ & 16.10 \\
\hline $40-45$ & 20.34 & & & & & & & More than 20 & 12.71 \\
\hline Above 45 & 8.47 & & & & & & & & \\
\hline
\end{tabular}

high satisfaction. J. X. Chen and J. Y. Chen [9] advocated the importance of buy back contract for distributor. Li et al. [10] studied 196 organizations and used structural equation modeling for processing the data and found that competitive advantage has a direct, positive impact on organizational performance. An organization offering high quality services can charge premium prices and thus increase its profit margin on sales and return on investment but this is possible due to quality data and reporting. An organization having a short time to market and rapid innovation can be the first in the market, thus enjoying a higher market share and sales volume. They also indicate that financial performances have close relationship with market performances.

Elahi et al. [11] discussed the need of good strategy and buy back contract to increase the confidence among the customers, while many industry experts are in favour of profit sharing among the entire supply chain elements. Also industry experts believe that attitude and welfare activities are the keys to judge the service quality of any organization. De Treville et al. [12] studied three different types of organizations and found that short lead time increases the market share through sales growth. Albernaz et al. [13] studied the oil company supply chain and identified the overall benefits of effective logistics to distributor as reduction in lead time, cost reduction, and obtaining production space in the production plant. Chang et al. [14] examined the industries of semiconductors, computer and peripheral equipment, optoelectronic products, communications and internet, electronic parts and components, electronic products distribution, and other electronic goods and concluded that the competitive advantages have direct relationship with financial performances.

Many researchers [15-17] have calculated the service quality for various organizations but authors have not come across any research work related to service quality in which the value of service quality was calculated by fuzzy graph theoretic approach. Fuzzy logic is used for incomplete, vague, or uncertain data whereas graph theoretic approach is used to convert intangible item into tangible. This technique was used by Goyal and Grover [18] for evaluation of advanced manufacturing technologies and Gupta and Singh [19] to compare the importance of various factors affecting the service quality of distributor. With the use of this technique, the intangible attributes convert into crisp score which further convert into single numerical index with the use of graph theoretic approach. The purpose of this study is to keep an eye on distributor by calculating the service quality provided and also to generate an alternate method for that. This can be done not just by identifying the factors, but by grouping the factors and developing a model using inheritance and interactions among factors identified to calculate the distributor service quality (DSQ) in quantitative term.

\section{Techniques Used}

To achieve the objective of this paper a questionnaire based survey, exploratory factor analysis (EFA), fuzzy logic (FL), and graph theoretic approach (GTA) have been used. The following sections discuss these methods.

2.1. Questionnaire Based Survey. A questionnaire based on identified factors was designed which comprised questions related to expectations/desire from distributor $\mathrm{X}$ and what the organization and retailers actually received from the same distributor. The data collection approach (by survey) was used as it has been used earlier by many researchers [15, 20, 21] in context of SCM. Snowball sampling was used to collect the data as the authors knew only a few persons in the entire supply chain. The responses were obtained on a five-point Likert scale. In the Likert five-point scale, 1 represents lowest or strongly disagree while 5 represents highest or strongly agree. Earlier different service quality studies [15, 22] motivate the authors to choose the five-point Likert scale. The designed questionnaire was filled by the person of the organization and retailers which came in contact with the distributor directly or indirectly on daily basis. All the persons involved in the survey held ample experience. The persons whose experience was less than one year were not involved in the survey.

The questionnaire consisted of two parts: the first part concentrated on the demographic information and the second on the items related to service quality of distributor. Demographic information included the respondent's age, sex, qualification, and experience, details of which are given in Table 1. Out of total 350 responses from managers of different departments and designations, 118 responses were completely filled. So, approximately $33.71 \%$ responses were completely filled.

2.2. Exploratory Factor Analysis. EFA is a multivariate statistical technique widely used in social and behavioral science and commonly used to explore the dimensionality of a measurement. The SPSS version 20 was used for this purpose. The main objective of using EFA in this paper is to group the 
TABLE 2: Conversion of fuzzy number into crisp score.

\begin{tabular}{llcc}
\hline Intangible factor & Intangible factor meaning & Fuzzy number & Crisp score \\
\hline Poor & One factor is very less important than the other & $D_{1}$ & 0.115 \\
Fair & One factor is less important than the other & $D_{2}$ & 0.295 \\
Good & Both factors are equally important & $D_{3}$ & 0.495 \\
Very good & One factor is much important than the other & $D_{4}$ & 0.695 \\
Excellent & One factor is very much important than the other & $D_{5}$ & 0.895 \\
\hline
\end{tabular}

factors into various subgroups to make calculations simpler. The following steps were used during performing the EFA:

(1) Identify the variable from the available literature and from the discussion with industry experts.

(2) Reliability test is to be performed to check the internal consistency. For this Cronbach's alpha should be greater than 0.7 .

(3) To check whether the sample size is adequate or not, KMO (Kaiser-Meyer-Olkin) sample of adequacy and significant value test were performed. If the value of $\mathrm{KMO}$ is greater than 0.6 and the value for significant value test is less than 0.005 , this indicates that data size is sufficient for grouping the various relevant factors; otherwise sample size is not adequate.

(4) Extract initial factors (via principal component analysis).

(5) Group the factors having highest values.

2.3. Fuzzy Logic. The concept of fuzzy logic (FL) was developed by Professor Zadeh et al. in 1965 as a mathematical tool for dealing with imprecise data but the application of this tool was found in industry in 1980 by Ebrahim Mamdani of Queen Mary College in London for controlling of a steam generator. After this fuzzy logic was used in neural network, control system, modeling and analysis, decision making, scheduling problems to minimize lateness, traffic management, railway applications, and so forth [23]. Sometime it is not possible to get accurate data from respondents due to certain limitations. Also sometimes the detail is in linguistic form instead of numeral. Under these conditions FL can be used. FL is a problem solving methodology that provides a simple way to arrive at a definite conclusion based upon vague, ambiguous, imprecise, noisy, or missing input information. The utility of fuzzy logic lies in its ability to provide decision for uncertain data. In FL all the values are 0.0 to 1.0 where 0.0 means absolute false or wrong and 1.0 means absolute truth or right. The following steps were used during performing FL.

(a) Convert all the fuzzy data, which is in linguistic or vague or noisy form, into fuzzy number and then these fuzzy numbers convert into crisp score. Tzeng and Huang [24] computed the crisp score based on the following equations:

$$
\mu_{\max }(y)= \begin{cases}y, & 0 \leq y \leq 1 \\ 0, & \text { otherwise }\end{cases}
$$

$$
\mu_{\min }(y)= \begin{cases}1-y, & 0 \leq y \leq 1 \\ 0, & \text { otherwise }\end{cases}
$$

The maximum and minimum fuzzy numbers must be selected in such a manner that they can automatically fit into comparison scale. The left and right scores of the fuzzy number are calculated as follows:

$$
\begin{aligned}
& \mu_{L}\left(W_{i}\right)=\operatorname{Sup}_{y}\left\{\mu_{\min }(y)^{\mu_{w i}(y)}\right\}, \\
& \mu_{R}\left(W_{i}\right)=\operatorname{Sup}_{y}\left\{\mu_{\max }(y)^{\mu_{w i}(y)}\right\} .
\end{aligned}
$$

The total score of (2) is given as follows:

$$
\mu_{T}\left(W_{i}\right)=\frac{\left\{\mu_{R}\left(W_{i}\right)+1-\mu_{L}\left(W_{i}\right)\right\}}{2} .
$$

By using (1)-(3), Tzeng and Huang [24] computed the crisp score shown in Table 2.

(b) Calculate the normalized score of the factors. To calculate the normalized score first of all find the mean value of response for all the factors individually and then use the following formula:

$$
\text { Normalized value }=\frac{M}{M_{\max }},
$$

where $M$ is the mean value of responses for an individual factor and $M_{\max }$ is the maximum mean value of any factor in the same group. This normalized value can be used as inheritance value for calculating the permanent function in graph theory.

(c) Convert all the factors into crisp score of fuzzy logic by using Table 2 . For getting fuzzy score, find the pairwise difference of mean of two factors for all the groups.

(d) Compute the mean range on 5-point scale modification for pairwise difference. The reason for computing the mean range on 5-point scale is getting the responses of questionnaire on 5-point scale.

(e) Convert this pairwise difference into crisp score.

2.4. Graph Theoretic Approach. Graph theoretic approach (GTA) consists of digraph, matrix, and permanent function representation. It converts the intangible factors into tangible and is used to calculate the single numerical index for any issue. This powerful technique was developed by Euler in 


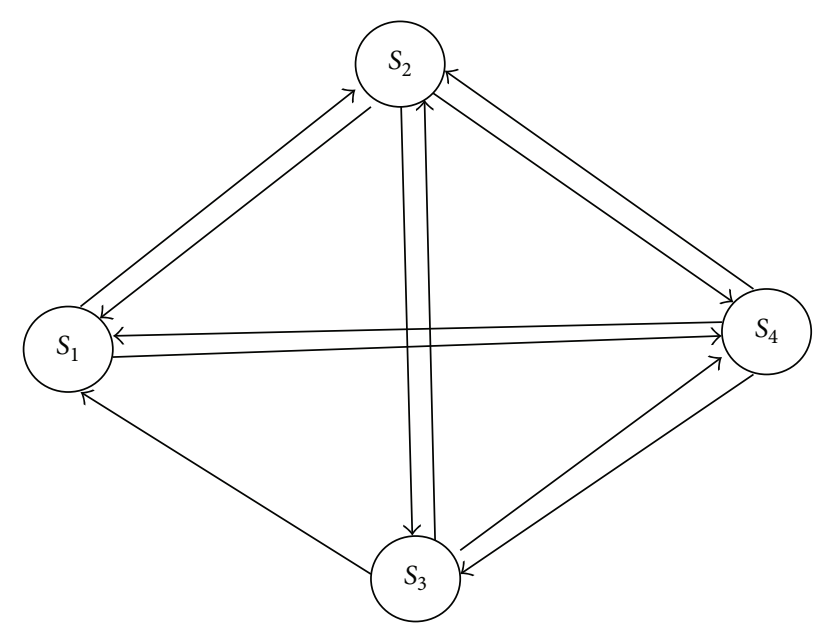

FIGURE 1: Schematic representation of four attributes and their interdependencies for a system.

1736 when he solved the famous Konigsberg bridge problem. After that, this technique was used by many researchers and practitioners in various fields [25]. This technique consists of the following components:

(1) Digraph representation.

(2) Matrix representation.

(3) Permanent function representation.

2.4.1. Digraph Representation. A digraph is a direction assigned graph used to represent the factors and their interdependencies in terms of nodes and edges. The SCM digraph represents the SCM factors $\left(S_{i}\right.$ 's $)$ through its nodes and edges and their dependencies $\left(S_{i j}\right.$ 's). $S_{i j}$ indicates the degree of dependence of the $j$ th factor on $i$ th factor. The four broad factors identified in Step 7 of Section 3 form the SCM digraph. All these four factors are schematically represented in Figure 1.

2.4.2. Matrix Representation. Matrix representation of SCM gives one to one representation and this matrix is known as variable permanent matrix for supply chain management (VPM-SCM). VPM-SCM representing the digraph shown in Figure 1 is given below:

$$
\begin{array}{r}
\text { VPM-SCM = } \\
1 \\
3 \\
4
\end{array} \quad\left(\begin{array}{cccc}
1 & 2 & 3 & 4 \\
S_{1} & S_{12} & S_{13} & S_{14} \\
S_{21} & S_{2} & S_{23} & S_{24} \\
S_{31} & S_{32} & S_{3} & S_{34} \\
S_{41} & S_{42} & S_{43} & S_{4}
\end{array}\right) .
$$

Diagonal components are known as inheritance components and their values are known as inheritance values while off diagonal components are known as interaction components and their values are known as interaction values.
2.4.3. Permanent Function Representation. Both digraph and matrix representations never give a clear result which can be compared or discussed. Permanent function is a solution for this problem. The permanent function is obtained in a similar manner as determinant with a difference that all negative signs are replaced by positive sign. The expression for permanent function which is also known as variable permanent function for supply chain management (VPFSCM) corresponding to 4 factor digraph is given by

$$
\begin{aligned}
& \text { VPF-SCM }=\text { per } S^{*}=\prod_{1}^{4} S_{i}+\sum_{i} \sum_{j} \sum_{k} \sum_{l}\left(S_{i j} \cdot S_{j i}\right) S_{k} S_{l} \\
& +\sum_{i} \sum_{j} \sum_{k} \sum_{l}\left(S_{i j} \cdot S_{j k} \cdot S_{k i}+S_{i k} \cdot S_{k j} \cdot S_{j i}\right) S_{l} \\
& +\left(\sum_{i} \sum_{j} \sum_{k} \sum_{l}\left(S_{i j} \cdot S_{j k}\right)\left(S_{k l} \cdot S_{l k}\right)\right. \\
& \left.\quad+\sum_{i} \sum_{j} \sum_{k} \sum_{l}\left(\left(S_{i j} \cdot S_{j k} \cdot S_{k l} \cdot S_{l i}\right)+\left(S_{i l} \cdot S_{l k} \cdot S_{k j} \cdot S_{j i}\right)\right)\right)
\end{aligned}
$$

The permanent function (see (5)) is a mathematical expression in symbolic form. Equation (5) contains terms arranged in $N+1$ group, where $N$ is the number of elements, which is 4 in this case. The total number of terms are $N$ !, that is, 4 ! or 24 in this case. The physical significance of various groups is explained below:

(1) The first grouping indicates a set of $N$ unconnected SCM elements, that is, $S_{1}, S_{2}, \ldots, S_{N}$.

(2) The second grouping indicates the self-loops which is absent in this case.

(3) The third grouping indicates a set of two-element SCM loops (i.e., $S_{i j} S_{j i}$ ).

(4) The fourth grouping indicates a set of three-element SCM loops (i.e., $S_{i j} S_{j k} S_{k i}$ or its pair $S_{i k} S_{k j} S_{j i}$ ).

(5) The fifth grouping consists of two subgroups. The first subgrouping indicates a set of two-element SCM loops (i.e., $S_{i j} S_{j i}$ and $S_{k l} S_{l k}$ ). The second subgrouping indicates a set of four-element SCM loops (i.e., $S_{i j} S_{j k} S_{k l} S_{l i}$ or its pair $\left.S_{i l} S_{l k} S_{k j} S_{j i}\right)$.

\section{Algorithm to Find DSQ by Fuzzy Graph Theoretic Approach (FGTA)}

The FGTA evaluates the supply chain performance in terms of a single numerical index for vague, ambiguous, imprecise, noisy, or missing input information. This considers the inheritance effect of factors and their interdependencies.

The various steps in the proposed approach are shown in Figure 2 and discussed here, which will help in the evaluation process of the supply chain performance.

Step 1 (identify the various factors). The total 19 factors were identified with the literature and industry experts. All of the 19 factors and their sources are presented in Table 3. 
TABLE 3: Identified factors and their sources.

\begin{tabular}{|c|c|}
\hline Factors & Sources \\
\hline Competitive advantages & Kessler and Chakrabarti [26], Tracey et al. [27], Li et al. [10], Thatte et al. [28], Albernaz et al. [13] \\
\hline Lead time & Viswanadham [29], Krajewski and Ritzman [30], Özer and Uncu [31], De Treville et al. [12] \\
\hline Buy back contract & Elahi et al. [11], J. X. Chen and J. Y. Chen [9] \\
\hline Logistics & ABL [32], Sadler and Hines [33], Giannetti et al. [34], Albernaz et al. [13] \\
\hline Price & Beamon [35], Li et al. [36], Luning et al. [37], Gunasekaran et al. [38], Li et al. [10], Yushi and Yuri [39] \\
\hline Financial performances & $\begin{array}{l}\text { Jacobson and Aaker [40], Vickery et al. [41], Li et al. [10], Kaynak and Hartley [42], Teller [43], Chang et } \\
\text { al. [14] }\end{array}$ \\
\hline Capacity & Krajewski and Ritzman [30] \\
\hline Delivery & Krajewski and Ritzman [30], Coyle et al. [44] \\
\hline Quality data reporting & $\begin{array}{l}\text { Saraph et al. [45], Deming [46], Crosby [47], Black and Porter [48], Adam et al. [49], Ho et al. [50], } \\
\text { Kaynak [51] }\end{array}$ \\
\hline Inventory level & Viswanadham [29] \\
\hline Efficiency & Beamon [35], Li et al. [10] \\
\hline Strategy & Hicks et al. [52], Elahi et al. [11] \\
\hline Time to market & $\begin{array}{l}\text { Beamon [35], Kessler and Chakrabarti [26], Li et al. [36], Luning et al. [37], Gunasekaran et al. [38], Li et } \\
\text { al. [10], Israel and Moskowitz [53] }\end{array}$ \\
\hline Sales growth & Beamon [35], Li et al. [36], Luning et al. [37], Gunasekaran et al. [38], Li et al. [10] \\
\hline Traceability & Calder and Marr [54], Viaene and Verbeke [55] \\
\hline Safety & $\mathrm{ABL}[32]$, industry expert \\
\hline Profit sharing & Elahi et al. [11], Altug and Van Ryzin [56], industry expert \\
\hline Attitude & Haywood-Farmer [57], industry expert \\
\hline Welfare activity & Industry expert \\
\hline
\end{tabular}

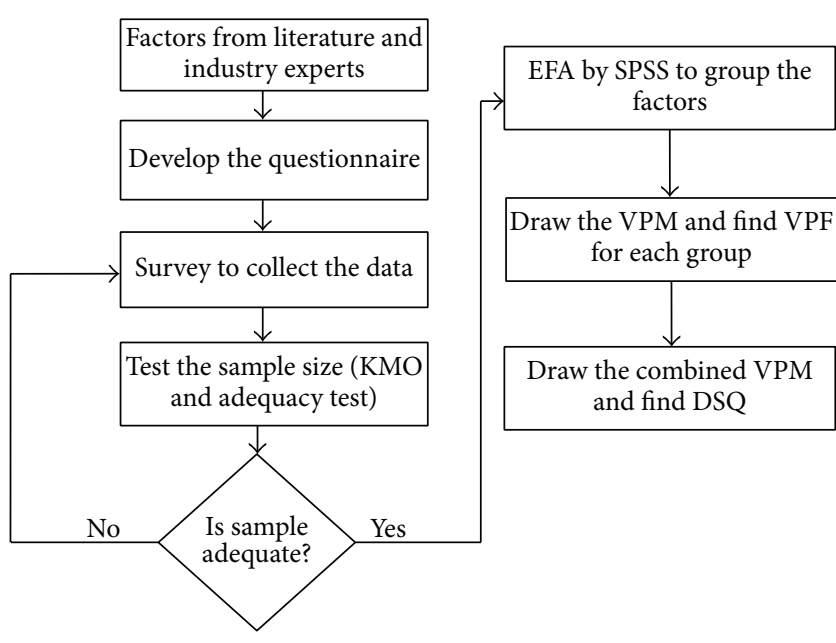

FIgURE 2: Process adopted to find the DSQ.

Step 2 (develop the questionnaire). A questionnaire was developed and survey conducted to get the data. Out of total 350 responses from managers of different departments and designations, 118 responses were completely filled. So, approximately $33.71 \%$ responses were completely filled.

Step 3 (test the sample size). (a) The value of Cronbach's alpha is 0.817 . So data is reliable.

(b) The KMO value is 0.688 and the value of significant value test is 0.000 which indicate that data size is sufficient
TABLE 4: KMO and Bartlett's test.

\begin{tabular}{lc}
\hline Kaiser-Meyer-Olkin measure of sampling adequacy & 0.688 \\
Bartlett's test of sphericity & \\
Approx. Chi-square & 530.874 \\
Df & 190 \\
Sig. & 0.000 \\
\hline
\end{tabular}

for grouping the various relevant factors. Table 4 shows the results of KMO test and significant value test.

Step 4 (use the exploratory factor analysis). EFA by SPSS version 20 was used to group the related factors. The score of EFA is shown in Table 5(a) and based on this score all the factors of Table 1 grouped into four major subgroups shown in Table 5(b).

Step 5 (convert fuzzy data into crisp score). (a) Convert all the fuzzy data into fuzzy number which is in linguistic or vague or noisy form and then into crisp score.

(b) The maximum and minimum fuzzy numbers must be selected in such a manner that they can automatically fit into comparison scale.

(c) Find the mean value of response for all the factors individually (Table 6) and then calculate the normalized score of the factors (Table 7). This normalized value can be used as inheritance value for calculating the permanent function in graph theory. 
TABLE 5: (a) Score of EFA. (b) Distribution of factors into various subgroups based on Table 5(a).

(a)

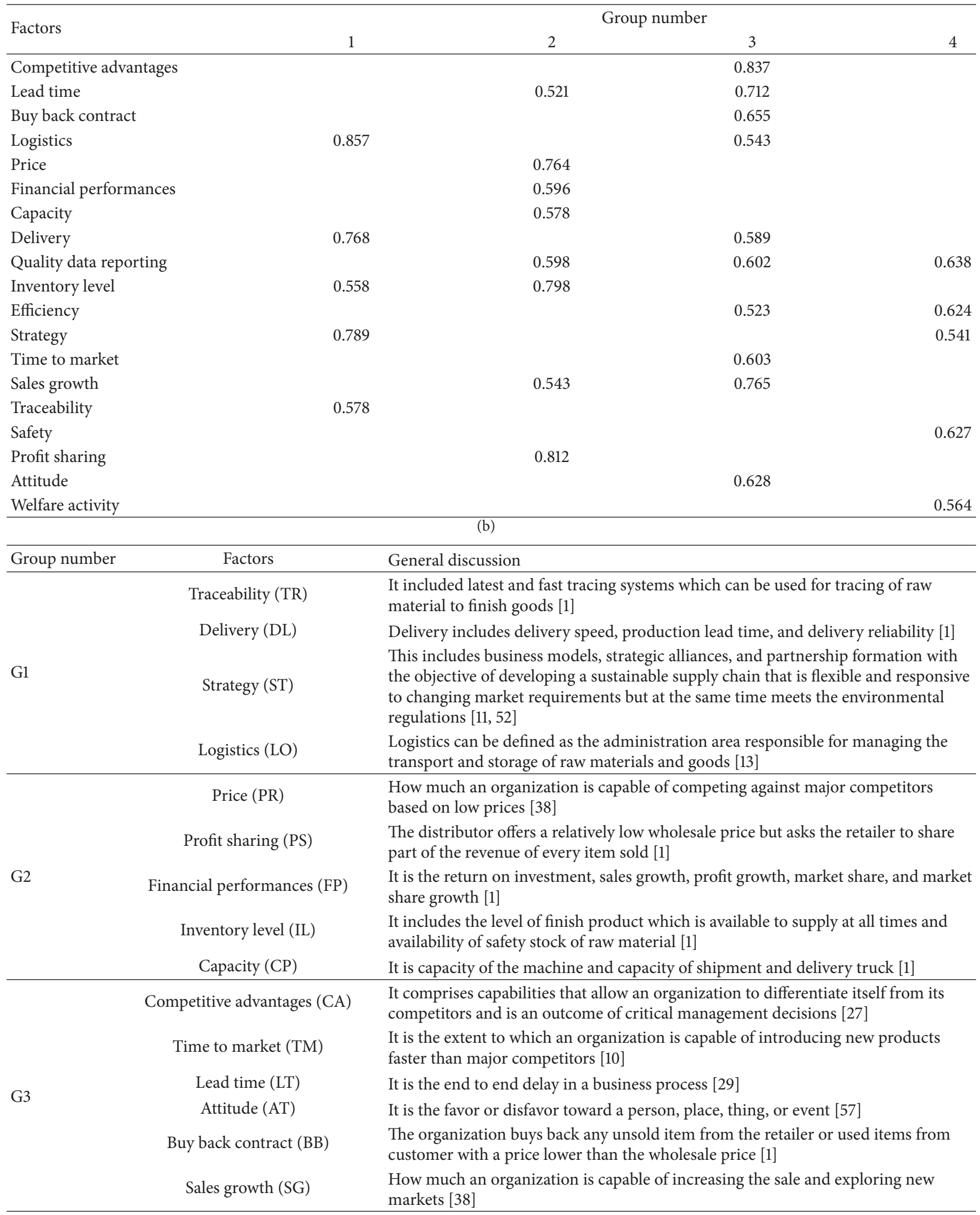


(b) Continued.

\begin{tabular}{|c|c|c|}
\hline Group number & Factors & General discussion \\
\hline \multirow[t]{4}{*}{ G4 } & Quality data reporting (QD) & $\begin{array}{l}\text { Saraph et al. [45] discussed the quality data and reporting factors to be the } \\
\text { (a) use of quality cost data, } \\
\text { (b) feedback of quality data to employees and managers for problem solving, } \\
\text { (c) timely quality measurement, } \\
\text { (d) evaluation of managers and employees based on quality performance, } \\
\text { (e) availability of quality data }\end{array}$ \\
\hline & Efficiency (EF) & $\begin{array}{l}\text { It considers operation cost, inventory cost, waste cost, transportation cost, labor } \\
\text { cost, and profit [1] }\end{array}$ \\
\hline & Safety (SF) & It is safety during processing, storing, transporting, and using the product [32] \\
\hline & Welfare activity (WA) & It considers the various charity program organized by the distributor \\
\hline
\end{tabular}

TABLE 6: Mean value of distributor service quality factors.

\begin{tabular}{|c|c|c|c|c|c|c|}
\hline G1 & $\begin{array}{c}\text { Traceability } \\
3.325\end{array}$ & $\begin{array}{c}\text { Delivery } \\
3.700\end{array}$ & $\begin{array}{c}\text { Strategy } \\
3.425\end{array}$ & $\begin{array}{c}\text { Logistics } \\
3.525\end{array}$ & & \\
\hline \multirow{2}{*}{ G2 } & Price & Profit sharing & Financial performances & Inventory level & Capacity & \\
\hline & 2.925 & 3.250 & 4.450 & 4.425 & 4.075 & \\
\hline \multirow{2}{*}{ G3 } & Competitive advantages & Time to market & Lead time & Attitude & Buy back contract & Sales growth \\
\hline & 4.175 & 3.425 & 4.025 & 3.575 & 3.225 & 3.125 \\
\hline \multirow{2}{*}{ G4 } & Quality data reporting & Efficiency & Safety & Welfare activity & & \\
\hline & 3.375 & 3.975 & 3.275 & 2.825 & & \\
\hline
\end{tabular}

TABLE 7: Normalized value of service quality factors (inheritance value).

\begin{tabular}{|c|c|c|c|c|c|c|}
\hline G1 & $\begin{array}{c}\text { Traceability } \\
0.90\end{array}$ & $\begin{array}{c}\text { Delivery } \\
1.00\end{array}$ & $\begin{array}{c}\text { Strategy } \\
0.93\end{array}$ & $\begin{array}{c}\text { Logistics } \\
0.95\end{array}$ & & \\
\hline \multirow{2}{*}{ G2 } & Price & Profit sharing & Financial performances & Inventory level & Capacity & \\
\hline & 0.66 & 0.73 & 1.00 & 0.99 & 0.92 & \\
\hline G3 & $\begin{array}{c}\text { Competitive advantages } \\
1.00\end{array}$ & $\begin{array}{c}\text { Time to market } \\
0.82\end{array}$ & $\begin{array}{l}\text { Lead time } \\
0.96\end{array}$ & $\begin{array}{l}\text { Attitude } \\
0.86\end{array}$ & $\begin{array}{c}\text { Buy back contract } \\
0.77\end{array}$ & $\begin{array}{c}\text { Sales growth } \\
0.75\end{array}$ \\
\hline G4 & $\begin{array}{l}\text { Quality data reporting } \\
0.85\end{array}$ & $\begin{array}{c}\text { Efficiency } \\
1.00\end{array}$ & $\begin{array}{c}\text { Safety } \\
0.82\end{array}$ & $\begin{array}{c}\text { Welfare activity } \\
0.71\end{array}$ & & \\
\hline
\end{tabular}

(d) Convert all the factors into crisp score of fuzzy logic by using Table 2. For getting fuzzy score, find the pairwise difference of mean of two factors for all the groups as shown in Table 8. As for group 1 first row, the mean value of traceability is 3.325 and all the values are subtracted individually from the value of traceability and similar method was adopted for all other values.

Compute the mean range on 5-point scale modification for pairwise difference as shown in Table 9. The reason for computing the mean range on 5-point scale is getting the responses of questionnaire on 5-point scale.

Then prepare Table 10 with the help of Tables 8 and 9. As for group 1, the crisp score for the value of -0.375 of Table 8 will be 0.115 from Table 9 and similar method was adopted to convert the values of groups 1, 2, 3, and 4 factors into crisp score.

Step 6 (develop the digraph for different individual groups and find permanent function). (a) Logically develop the digraphs between the factors of different groups depending on their interdependencies. The relations between various factors depend on the responses of industries expert. The nodes in the digraph represent factors while edges represent interaction among factors. Figures 3(a), 3(b), 3(c), and 3(d) showing the digraph for factors of groups $1,2,3$, and 4 , respectively, and the values of Table 7 can be used for inheritance value and the values of Table 10 can be used for interactions value of factors.

In Figure 3(a), all four factors of G1 and their interrelations are shown. These interrelations are based on the discussions with industry experts. Traceability and delivery have direct relation with all the factors while strategy and logistics have no dependence on traceability.

In Figure 3(b), all five factors of G2 and their interrelations are shown. Again these interrelations are based on the discussions with industry experts. The price and financial performances of any product depend on all the factors. Profit sharing depends on price and financial performances. Inventory level depends on the price of the product and the financial performances and capacity depend on the price, profit sharing, and financial performances.

In Figure 3(c), all six factors of G3 and their interrelations are shown. Again these interrelations are based on the discussions with industry experts. Competitive advantages and attitude depend on all the factors, while time to market depends on two factors, that is, competitive advantages and 
TABLE 8: Pairwise difference between various groups.

\begin{tabular}{|c|c|c|c|c|c|c|c|c|c|c|c|c|c|c|c|c|c|c|c|}
\hline Factors & s TR & DL & ST & LO & PR & PS & FP & IL & CP & CA & TM & $\mathrm{LT}$ & $\mathrm{AT}$ & $\mathrm{BB}$ & SG & QD & EF & SF & WA \\
\hline $\mathrm{TR}$ & 0 & -0.375 & -0.1 & -0.2 & & & & & & & & & & & & & & & \\
\hline $\mathrm{DL}$ & 0.375 & 0 & 0.275 & 0.175 & & & & & & & & & & & & & & & \\
\hline ST & 0.1 & -0.275 & 0 & -0.1 & & & & & & & & & & & & & & & \\
\hline LO & 0.2 & -0.175 & 0.1 & 0 & & & & & & & & & & & & & & & \\
\hline $\mathrm{PR}$ & & & & & 0 & -0.325 & -1.525 & -1.5 & -1.15 & & & & & & & & & & \\
\hline PS & & & & & 0.325 & 0 & -1.2 & -1.175 & -0.825 & & & & & & & & & & \\
\hline FP & & & & & 1.525 & 1.2 & 0 & 0.025 & 0.375 & & & & & & & & & & \\
\hline IL & & & & & 1.5 & 1.175 & -0.025 & 0 & 0.35 & & & & & & & & & & \\
\hline $\mathrm{CP}$ & & & & & 1.15 & 0.825 & -0.375 & -0.35 & 0 & & & & & & & & & & \\
\hline PR & & & & & & & & & & 0 & -0.325 & -1.525 & -1.5 & -1.15 & 0 & & & & \\
\hline PS & & & & & & & & & & 0.325 & 0 & -1.2 & -1.175 & -0.825 & 0.325 & & & & \\
\hline FP & & & & & & & & & & 1.525 & 1.2 & 0 & 0.025 & 0.375 & 1.525 & & & & \\
\hline IL & & & & & & & & & & 1.5 & 1.175 & -0.025 & 5 & 0.35 & 1.5 & & & & \\
\hline CP & & & & & & & & & & 1.15 & 0.825 & -0.375 & -0.35 & 0 & 1.15 & & & & \\
\hline $\mathrm{PR}$ & & & & & & & & & & 0 & -0.325 & -1.525 & -1.5 & -1.15 & 0 & & & & \\
\hline QD & & & & & & & & & & & & & & & & 0 & -0.6 & 0.1 & 0.55 \\
\hline $\mathrm{EF}$ & & & & & & & & & & & & & & & & 0.6 & 0 & 0.7 & 1.15 \\
\hline SF & & & & & & & & & & & & & & & & -0.1 & -0.7 & 0 & 0.45 \\
\hline WA & & & & & & & & & & & & & & & & -0.55 & -1.15 & -0.45 & 0 \\
\hline
\end{tabular}

TABLE 9: Mean range on 5-point scale modification of Table 8.

\begin{tabular}{lcccc}
\hline \multirow{2}{*}{ Fuzzy number } & G1 & Mean range for factors of & G3 & G4 \\
\hline$D_{1}$ & -0.225 to -0.375 & -0.915 to -1.525 & -0.63 to -1.05 & -0.69 to -1.15 \\
$D_{2}$ & -0.075 to -0.225 & -0.305 to -0.915 & -0.21 to -0.63 & -0.23 to -0.69 \\
$D_{3}$ & -0.075 to 0.075 & -0.305 to 0.305 & -0.21 to 0.21 & -0.23 to 0.23 \\
$D_{4}$ & 0.075 to 0.225 & 0.305 to 0.915 & 0.21 to 0.63 & 0.23 to 0.69 \\
$D_{5}$ & 0.225 to 0.375 & 0.915 to 1.525 & 0.63 to 1.05 & 0.69 to 1.15 \\
\hline
\end{tabular}

TABLE 10: Conversion of Table 8 in relative importance with crisp score using Table 9.

\begin{tabular}{|c|c|c|c|c|c|c|c|c|c|c|c|c|c|c|c|c|c|c|c|}
\hline Factors & $\mathrm{TR}$ & $\mathrm{DL}$ & ST & LO & PR & PS & $\mathrm{FP}$ & IL & $\mathrm{CP}$ & $\mathrm{CA}$ & TM & LT & AT & $\mathrm{BB}$ & SG & QD & $\mathrm{EF}$ & SF & WA \\
\hline TR & 0 & 0.115 & 0.295 & 0.295 & & & & & & & & & & & & & & & \\
\hline $\mathrm{DL}$ & 0.895 & 0 & 0.895 & 0.695 & & & & & & & & & & & & & & & \\
\hline ST & 0.695 & 0.115 & 0 & 0.295 & & & & & & & & & & & & & & & \\
\hline LO & 0.695 & 0.295 & 0.695 & 0 & & & & & & & & & & & & & & & \\
\hline PR & & & & & 0 & 0.295 & 0.115 & 0.115 & 0.115 & & & & & & & & & & \\
\hline PS & & & & & 0.695 & 0 & 0.115 & 0.115 & 0.295 & & & & & & & & & & \\
\hline FP & & & & & 0.895 & 0.895 & 0 & 0.495 & 0.695 & & & & & & & & & & \\
\hline IL & & & & & 0.895 & 0.895 & 0.495 & 0 & 0.695 & & & & & & & & & & \\
\hline $\mathrm{CP}$ & & & & & 0.895 & 0.695 & 0.295 & 0.295 & 0 & & & & & & & & & & \\
\hline PR & & & & & & & & & & 0 & 0.895 & 0.495 & 0.695 & 0.895 & 0.895 & & & & \\
\hline PS & & & & & & & & & & 0.115 & 0 & 0.295 & 0.495 & 0.495 & 0.695 & & & & \\
\hline FP & & & & & & & & & & 0.495 & 0.695 & 0 & 0.695 & 0.895 & 0.895 & & & & \\
\hline IL & & & & & & & & & & 0.295 & 0.495 & 0.295 & 0 & 0.695 & 0.695 & & & & \\
\hline $\mathrm{CP}$ & & & & & & & & & & 0.115 & 0.495 & 0.115 & 0.295 & 0 & 0.495 & & & & \\
\hline PR & & & & & & & & & & 0.115 & 0.295 & 0.115 & 0.295 & 0.495 & 0 & & & & \\
\hline QD & & & & & & & & & & & & & & & & 0 & 0.295 & 0.495 & 0.695 \\
\hline $\mathrm{EF}$ & & & & & & & & & & & & & & & & 0.695 & 0 & 0.895 & 0.895 \\
\hline SF & & & & & & & & & & & & & & & & 0.495 & 0.115 & 0 & 0.695 \\
\hline WA & & & & & & & & & & & & & & & & 0.295 & 0.115 & 0.295 & 0 \\
\hline
\end{tabular}




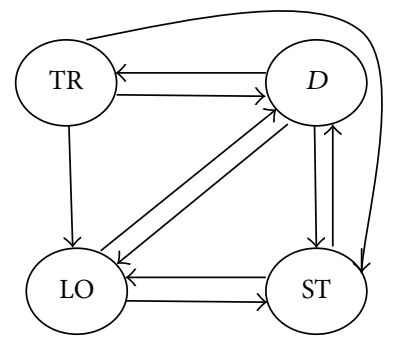

(a)

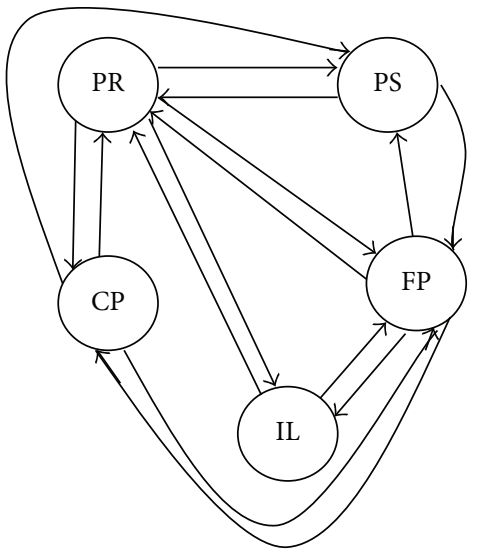

(b)

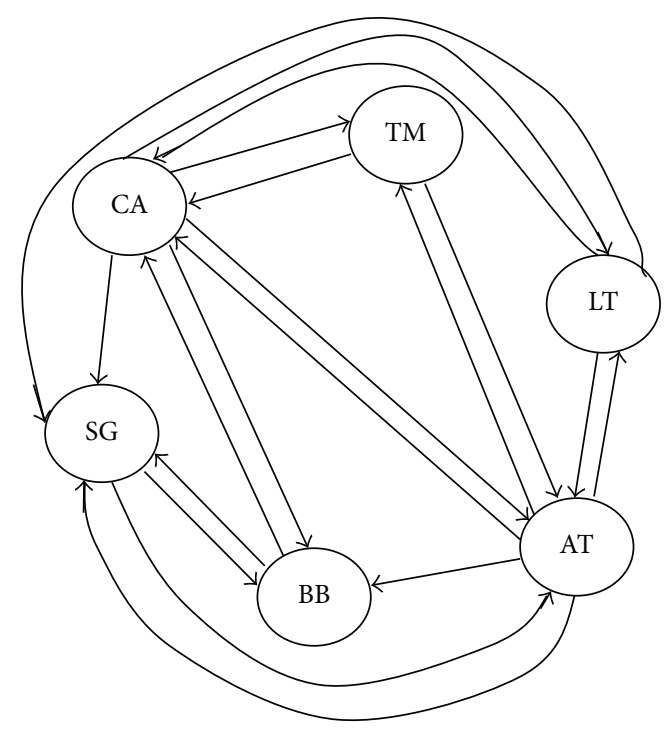

(c)

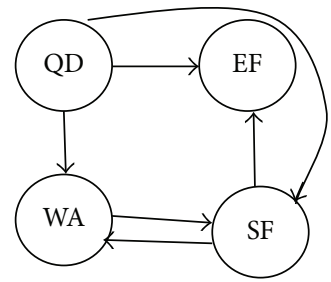

(d)

FiguRE 3: (a) Digraph of group 1 factors. (b) Digraph of group 2 factors. (c) Digraph of group 3 factors. (d) Digraph of group 4 factors.

attitude. Lead time depends on attitude, sales growth, and competitive advantages. Buy back contract depends on sales growth and competitive advantages and sales growth depends on attitude and buy back contract.

In Figure 3(d), all four factors of G4 and their interrelations are shown. These interrelations are based on the discussions with industry experts. Quality data reporting depends on the other three factors, safety depends on efficiency and welfare activities, and welfare activities depend on safety.

(b) Prepare the permanent matrix with the help of digraph. (M2), (M3), (M4), and (M5) are the permanent matrix for G-1, G-2, G-3, and G-4 factors. The inheritance values in the matrices ((M2), (M3), (M4), and (M5)) can be put from Table 7, while the interaction value can be put from Table 10. factor.

(c) Find the value of permanent function for each group

VPM for Group 1 Factors

$$
\text { VPM-G1 }=\begin{gathered}
\text { TR } \\
\text { DL } \\
\text { ST } \\
\text { LO }
\end{gathered}\left(\begin{array}{cccc}
S_{1} & S_{12} & S_{13} & S_{14} \\
S_{21} & S_{2} & S_{23} & S_{24} \\
0 & S_{32} & S_{3} & S_{34} \\
0 & S_{42} & S_{43} & S_{4}
\end{array}\right) .
$$

The inheritance, that is, diagonal values, can be taken from Table 7 and interaction, that is, off diagonal values, can be taken from Table 10, so VPM for group 1 factors is

VPM- G1

$$
\begin{gathered}
\text { TR } \\
\text { DL } \\
\text { ST } \\
\text { LO }
\end{gathered}\left(\begin{array}{cccc}
0.9 & 0.115 & 0.295 & 0.295 \\
0.895 & 1.0 & 0.895 & 0.695 \\
0 & 0.115 & 0.93 & 0.295 \\
0 & 0.295 & 0.695 & 0.95
\end{array}\right),
$$

VPF-G1 $=1.52$.

VPM for Group 2 Factors

VPM-G2

$$
\begin{gathered}
\mathrm{PR} \\
\mathrm{PS} \\
\mathrm{FP} \\
\mathrm{IL} \\
\mathrm{CP}
\end{gathered} \quad\left(\begin{array}{ccccc}
S_{1} & S_{12} & S_{13} & S_{14} & S_{15} \\
S_{21} & S_{2} & S_{23} & 0 & 0 \\
S_{31} & S_{32} & S_{3} & S_{34} & S_{35} \\
S_{41} & 0 & S_{43} & S_{4} & 0 \\
S_{51} & S_{52} & S_{53} & 0 & S_{5}
\end{array}\right) .
$$


The inheritance, that is, diagonal values, can be taken from Table 7 and interaction, that is, off diagonal values, can be taken from Table 10, so VPM for group 2 factors is

VPM-G2

$$
\begin{gathered}
\text { PR } \\
\text { PR } \\
\text { PS } \\
\text { PP } \\
\text { FP } \\
\text { IL } \\
\text { CP }
\end{gathered}\left(\begin{array}{ccccc}
0.66 & 0.295 & 0.115 & 0.115 & 0.115 \\
0.695 & 0.73 & 0.115 & 0 & 0 \\
0.895 & 0.895 & 1.0 & 0.495 & 0.695 \\
0.895 & 0 & 0.495 & 0.99 & 0 \\
0.895 & 0.895 & 0.295 & 0 & 0.92
\end{array}\right)
$$

VPF-G2 $=1.84$
VPM for Group 3 Factors

VPM-G3

$$
\left.\begin{array}{c}
\text { CA } \\
\text { TM } \\
= \\
\text { LT } \\
\text { AT } \\
\text { BB } \\
\text { SG }
\end{array} \quad \begin{array}{cccccc}
S_{1} & S_{12} & S_{13} & S_{14} & S_{15} & S_{16} \\
S_{21} & S_{2} & 0 & S_{24} & 0 & 0 \\
S_{31} & 0 & S_{3} & S_{34} & 0 & S_{36} \\
S_{41} & S_{42} & S_{43} & S_{4} & S_{45} & S_{46} \\
S_{51} & 0 & 0 & 0 & S_{5} & S_{56} \\
0 & 0 & 0 & S_{64} & S_{65} & S_{6}
\end{array}\right) .
$$

The inheritance, that is, diagonal values, can be taken from Table 7 and interaction, that is, off diagonal values, can be taken from Table 10, so VPM for group 3 factors is

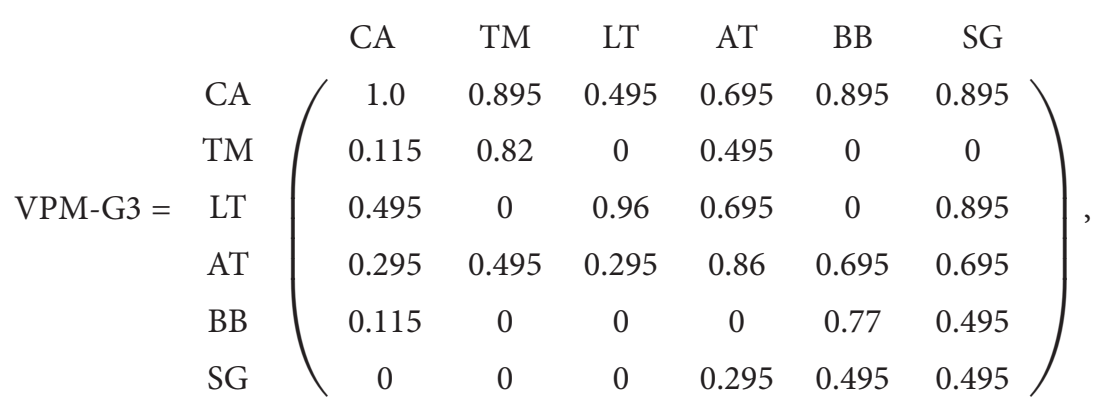

VPM for Group 4 Factors

$$
\text { VPM-G4 }=\begin{array}{cccc}
\text { QD } & \text { EF } & \text { SF } & \text { WA } \\
\text { EF } \\
\text { SF } \\
\text { WA }
\end{array} \quad\left(\begin{array}{cccc}
S_{1} & S_{12} & S_{13} & S_{14} \\
0 & S_{2} & 0 & 0 \\
0 & S_{32} & S_{3} & S_{34} \\
0 & 0 & S_{43} & S_{4}
\end{array}\right)
$$

The inheritance, that is, diagonal values, can be taken from Table 7 and interaction, that is, off diagonal values, can be taken from Table 10, so VPM for group 4 factors is

VPM-G4

$$
\begin{gathered}
\text { QD } \\
\text { QD } \\
\text { EF } \\
\text { SF } \\
\text { WA }
\end{gathered} \quad\left(\begin{array}{cccc}
0.85 & 0.295 & 0.495 & 0.695 \\
0 & 1.0 & 0 & 0 \\
0 & 0.115 & 0.82 & 0.695 \\
0 & 0 & 0.295 & 0.71
\end{array}\right) \text {, }
$$

VPF-G4 $=0.67$
Step 7 (develop the digraph for distributor and find permanent function). (a) Develop the digraph and performance matrix between various groups by the same method as explained in Step 6. Figure 4 shows the digraph between various groups.

(b) At group level, the permanent value of each group factor (obtained in Step 6) provides inheritance values of DSQ index. The quantitative value of interactions among factors is obtained from Table 5 through proper interpretation by experts. This will form variable permanent matrix (M6) at group level.

(c) Find the value of permanent function for the system. This is the value of the distributor service quality index. The performance of any distributor can thus be evaluated based on the above-discussed methodology.

VPM-D

$$
=\begin{array}{cccc}
\mathrm{G} 1 & \mathrm{G} 2 & \mathrm{G} 3 & \mathrm{G} 4 \\
\mathrm{G} 1 & \mathrm{G} 2 \\
\mathrm{G} 3 \\
\mathrm{G} 4
\end{array}\left(\begin{array}{cccc}
1.52 & 0.295 & 0.495 & 0.295 \\
0.695 & 1.84 & 0.495 & 0.295 \\
0.495 & 0.495 & 2.49 & 0.495 \\
0.695 & 0.695 & 0.495 & 0.67
\end{array}\right) \text {, }
$$




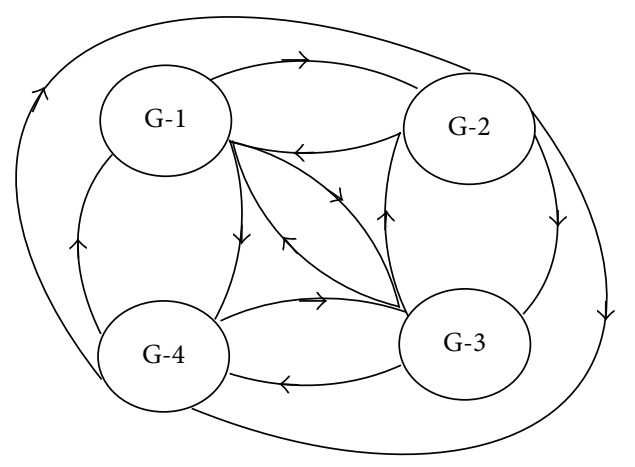

FIGURE 4: Schematic representation of distributor factors.

The result shows that the actual value of index of distributor service quality (DSQ) is 9.34. This result is for a leading two-wheeler manufacturing supply chain of North India. However, with the help of the above-discussed procedure, the service quality for any organization can be calculated.

\section{Conclusion}

The proposed methodology used a fuzzy graph theoretic approach, which is a powerful tool for finding a conclusion when there is a chance of uncertainty, vague data, or noisy data as no other techniques can be used under these conditions. This approach integrates all possible structural, functional, and performance parameters in a mathematical model for analysis and optimization. Services are ideas and concepts; products are things. Therefore, it follows that service innovations are not patentable. To secure the benefits of a novel service concept, the firm must expand extremely rapidly and preempt any competitors.

The hybrid technique presented in this paper can be used to convert intangible into tangible and as an aid to understand and develop a method to calculate the distributor service quality index. This would help the supply chain managers to compare the service quality of various distributors and suggest improvements needed, if they want to migrate from one model to another model of managing their supply chains in view of changing market requirements. This method can also be used as benchmark to take the decision for changing the distributor if he fails to provide good service quality.

\section{Competing Interests}

The authors declare that they have no competing interests.

\section{References}

[1] T. K. Gupta and V. Singh, "A systematic approach to evaluate supply chain management environment index using graph theoretic approach," International Journal of Logistics Systems and Management, vol. 21, no. 1, pp. 1-45, 2015.

[2] D. D. Shipley, "Selection and motivation of distribution intermediaries," Industrial Marketing Management, vol. 13, no. 4, pp. 249-256, 1984.
[3] S. T. Cavusgil, P.-L. Yeoh, and M. Mitri, "Selecting foreign distributors: an expert systems approach," Industrial Marketing Management, vol. 24, no. 4, pp. 297-304, 1995.

[4] D. Sharma, B. S. Sahay, and A. Sachan, "Modeling distributor performance index using system dynamic approach," Asia Pacific Journal of Marketing and Logistics, vol. 13, no. 3, pp. 3767, 2004.

[5] J.-S. C. Lin and C.-R. Chen, "Determinants of manufacturers' selection of distributors," Supply Chain Management, vol. 13, no. 5, pp. 356-365, 2008.

[6] S.-P. Chen and W.-Y. Wu, "A systematic procedure to evaluate an automobile manufacturer-distributor partnership," European Journal of Operational Research, vol. 205, no. 3, pp. 687-698, 2010.

[7] M. Ghorbani, R. Tavakkoli-Moghaddam, J. Razmi, and S. M. Arabzad, "Applying the fuzzy ART algorithm to distribution network design," Management Science Letters, vol. 2, no. 1, pp. 79-86, 2012.

[8] P. Jonsson and M. Zineldin, "Achieving high satisfaction in supplier-dealer working relationships," Supply Chain Management, vol. 8, no. 3, pp. 224-240, 2003.

[9] J. X. Chen and J. Y. Chen, "The model of distributor chain financing based on buy back guarantee contract," Journal of Applied Mathematics, vol. 2014, Article ID 902739, 7 pages, 2014.

[10] S. Li, B. Ragu-Nathan, T. S. Ragu-Nathan, and S. Subba Rao, "The impact of supply chain management practices on competitive advantage and organizational performance," Omega, vol. 34, no. 2, pp. 107-124, 2006.

[11] E. Elahi, N. Lamba, and C. Ramaswamy, "How can we improve the performance of supply chain contracts? An experimental study," International Journal of Production Economics, vol. 142, no. 1, pp. 146-157, 2013.

[12] S. De Treville, I. Bicer, V. Chavez-Demoulin et al., "Valuing lead time," Journal of Operations Management, vol. 32, no. 6, pp. 337346, 2014.

[13] H. Albernaz, U. G. Maruyama, M. S. Maciel, and F. R. Correa, "Implementation of distribution centers as logistics competitive advantage: study on oil company distributor in southeast Brazil," Independent Journal of Management \& Production, vol. 5, no. 4, pp. 1089-1106, 2014.

[14] M. C. Chang, Y.-H. Wang, J.-C. Hung, and C. Sun, "R\&D, patent arrangements, and financial performances: evidence from Taiwan," Periodica Polytechnica, Social and Management Sciences, vol. 23, no. 1, pp. 25-40, 2015.

[15] N. Seth, S. G. Deshmukh, and P. Vrat, "SSQSC: a tool to measure supplier service quality in supply chain," Production Planning and Control, vol. 17, no. 5, pp. 448-463, 2006.

[16] R. Jain, G. Sinha, and S. Sahney, A model of service quality in technical education: a student perspective [Ph.D. thesis], IIT, Kharagpur, India, 2012.

[17] S. Das and D. Pandit, Methodology to assess bus transit service quality based on user perception [Ph.D. thesis], IIT, Kharagpur, India, 2014.

[18] S. Goyal and S. Grover, "A fuzzy multi attribute decision making approach for evaluating effectiveness of advanced manufacturing technology-in Indian context," International Journal of Productivity and Quality Management, vol. 11, no. 2, pp. 150-178, 2013.

[19] T. Gupta and V. Singh, "Fuzzy graph theoretic approach to compare the factors affecting the service quality of distributors," International Journal of Applied Engineering Research, vol. 10, no. 78, pp. 182-186, 2015. 
[20] J. J. Cronin Jr. and S. A. Taylor, "Measuring service quality: a reexamination and extension," Journal of Marketing, vol. 56, no. 3, pp. 55-68, 1992.

[21] R. K. Teas, "Expectations, performance evaluation, and consumers' perceptions of quality," Journal of Marketing, vol. 57, no. 4, pp. 18-34, 1993.

[22] C. Grönroos, "A service quality model and its marketing implications," European Journal of Marketing, vol. 18, no. 4, pp. 36-44, 1984.

[23] A. P. Cucala, A. Fernández, C. Sicre, and M. Domínguez, "Fuzzy optimal schedule of high speed train operation to minimize energy consumption with uncertain delays and driver's behavioral response," Engineering Applications of Artificial Intelligence, vol. 25, no. 8, pp. 1548-1557, 2012.

[24] G.-H. Tzeng and J.-J. Huang, Multiple Attribute Decision Making-Methods and Applications, CRC Press, New York, NY, USA, 2011.

[25] T. Gupta and V. Singh, "Application of graph theory: a review," in Proceedings of the National Conference on Emerging Technologies in Mechanical Engineering at Echelon Institute of Technology, pp. 24-25, Faridabad, India, January 2014.

[26] E. H. Kessler and A. K. Chakrabarti, "Innovation speed: a conceptual model of context, antecedents, and outcomes," Academy of Management Review, vol. 21, no. 4, pp. 1143-1191, 1996.

[27] M. Tracey, M. A. Vonderembse, and J.-S. Lim, "Manufacturing technology and strategy formulation: keys to enhancing competitiveness and improving performance," Journal of Operations Management, vol. 17, no. 4, pp. 411-428, 1999.

[28] A. A. Thatte, S. S. Rao, and T. S. Ragu-Nathan, "Impact of SCM practices of a firm on supply chain responsiveness and competitive advantage of a firm," Journal of Applied Business Research, vol. 29, no. 2, pp. 499-530, 2013.

[29] N. Viswanadham, Analysis of Manufacturing Enterprises, Kluwer Academic, 2000.

[30] L. Krajewski and L. Ritzman, Operations Management: Strategy and Analysis, Prentice Hall, New York, NY, USA, 6th edition, 2002.

[31] Ö. Özer and O. Uncu, "Competing on time: an integrated framework to optimize dynamic time-to-market and production decisions," Production and Operations Management, vol. 22, no. 3, pp. 473-488, 2013.

[32] Australian Business Limited (ABL), Asian Food Buyers Survey, Agri Chain Solutions, 2001.

[33] I. Sadler and P. Hines, "Strategic operations planning process for manufacturers with a supply chain focus: concepts and a meat processing application," Supply Chain Management, vol. 7, no. 4, pp. 225-241, 2002.

[34] B. F. Giannetti, S. H. Bonilla, and C. M. V. B. Almeida, "An emergy-based evaluation of a reverse logistics network for steel recycling," Journal of Cleaner Production, vol. 46, pp. 48-57, 2013.

[35] B. M. Beamon, "Measuring supply chain performance," International Journal of Operations and Production Management, vol. 19, no. 3, pp. 275-292, 1999.

[36] S. Li, S. Rao, T. S. Ragu-Nathan, and B. Ragu-Nathan, "An empirical investigation of supply chain management practices," in Proceedings of the 33rd Annual Meeting of the Decision Science Institute, San Diego, Calif, USA, November 2002.

[37] P. A. Luning, W. J. Marcelis, and W. M. F. Jongen, Food Quality Management: A Techno-Managerial Approach, Wageningen Pers, Wageningen, The Netherlands, 2002.
[38] A. Gunasekaran, C. Patel, and R. E. McGaughey, "A framework for supply chain performance measurement," International Journal of Production Economics, vol. 87, no. 3, pp. 333-347, 2004.

[39] Y. Yushi and S. Yuri, "Automobile exports: export price and retail price," RIETI Discussion Paper Series 15-E-024, 2015.

[40] R. Jacobson and D. A. Aaker, "The strategic role of product quality," Journal of Marketing, vol. 51, no. 4, pp. 31-44, 1987.

[41] S. K. Vickery, C. Droge, and R. E. Markland, "Production competence and business strategy: do they affect business performance?" Decision Sciences, vol. 24, no. 2, pp. 435-456, 1993.

[42] H. Kaynak and J. L. Hartley, "A replication and extension of quality management into the supply chain," Journal of Operations Management, vol. 26, no. 4, pp. 468-489, 2008.

[43] J. Teller, "Portfolio risk management and its contribution to project portfolio success: an investigation of organization, process, and culture," Project Management Journal, vol. 44, no. 2, pp. 36-51, 2013.

[44] J. J. Coyle, E. J. Bardi, and J. Langley, The Management of Business Logistics, Thomson South-Western, Mason, Ohio, USA, 2003.

[45] J. V. Saraph, P. G. Benson, and R. G. Schroeder, "An instrument for measuring the critical factors of quality management," Decision Sciences, vol. 20, no. 4, pp. 810-829, 1989.

[46] W. E. Deming, The New Economics for Industry, Government Education, Massachusetts Institute of Technology, Center for Advanced Engineering Study, Cambridge, Mass, USA, 1993.

[47] L. A. Crosby, Consumer Attitudes toward Whole Life Insurance Atlanta, Life Office Management Association, 1984.

[48] S. A. Black and L. J. Porter, "Identification of the critical factors of TQM," Decision Sciences, vol. 27, no. 1, pp. 1-21, 1996.

[49] E. E. Adam, L. M. Corbett, B. E. Flores et al., "An international study of quality improvement approach and firm performance," International Journal of Operations and Production Management, vol. 17, no. 9, pp. 842-873, 1997.

[50] D. C. K. Ho, V. G. Duffy, and H. M. Shih, "Total quality management: an empirical test for mediation effect," International Journal of Production Research, vol. 39, no. 3, pp. 529-548, 2001.

[51] H. Kaynak, "The relationship between total quality management practices and their effects on firm performance," Journal of Operations Management, vol. 21, no. 4, pp. 405-435, 2003.

[52] C. Hicks, T. McGovern, and C. F. Earl, "Supply chain management: a strategic issue in engineer to order manufacturing," International Journal of Production Economics, vol. 65, no. 2, pp. 179-190, 2000.

[53] R. Israel and T. J. Moskowitz, "The role of shorting, firm size, and time on market anomalies," Journal of Financial Economics, vol. 108, no. 2, pp. 275-301, 2013.

[54] R. Calder and P. Marr, "A beef producer initiative in traceability: scottish borders TAG," Supply Chain Management, vol. 3, no. 3, pp. 123-126, 1998.

[55] J. Viaene and W. Verbeke, "Traceability as a key instrument towards supply chain and quality management in the Belgian poultry meat chain," Supply Chain Management, vol. 3, no. 3, pp. 139-141, 1998.

[56] M. S. Altug and G. Van Ryzin, "Is revenue sharing right for your supply chain?" California Management Review, vol. 56, no. 4, pp. 53-81, 2014.

[57] J. Haywood-Farmer, "A conceptual model of service quality," International Journal of Operations and Production Management, vol. 8, no. 6, pp. 19-29, 1988. 


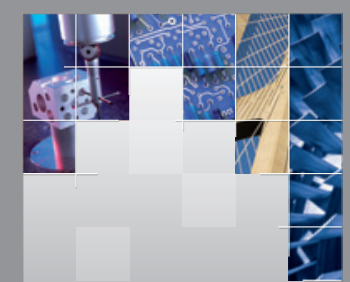

\section{Enfincering}
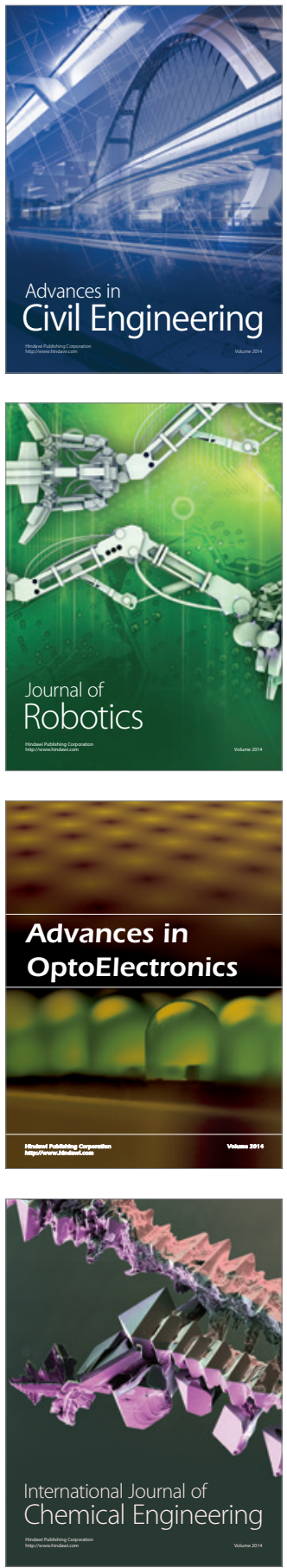

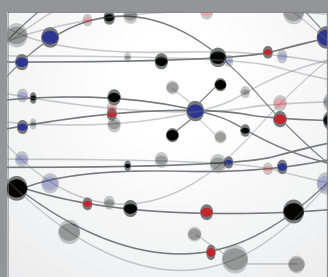

The Scientific World Journal

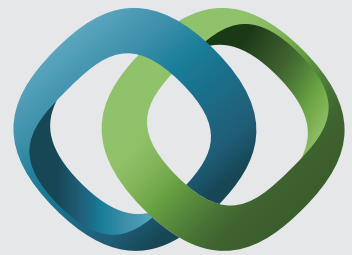

\section{Hindawi}

Submit your manuscripts at

http://www.hindawi.com
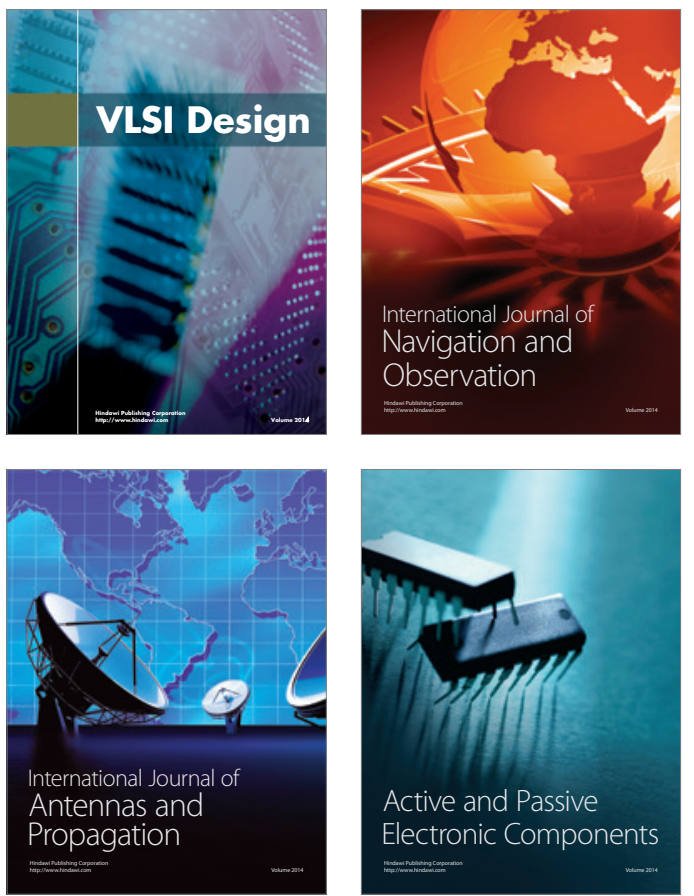
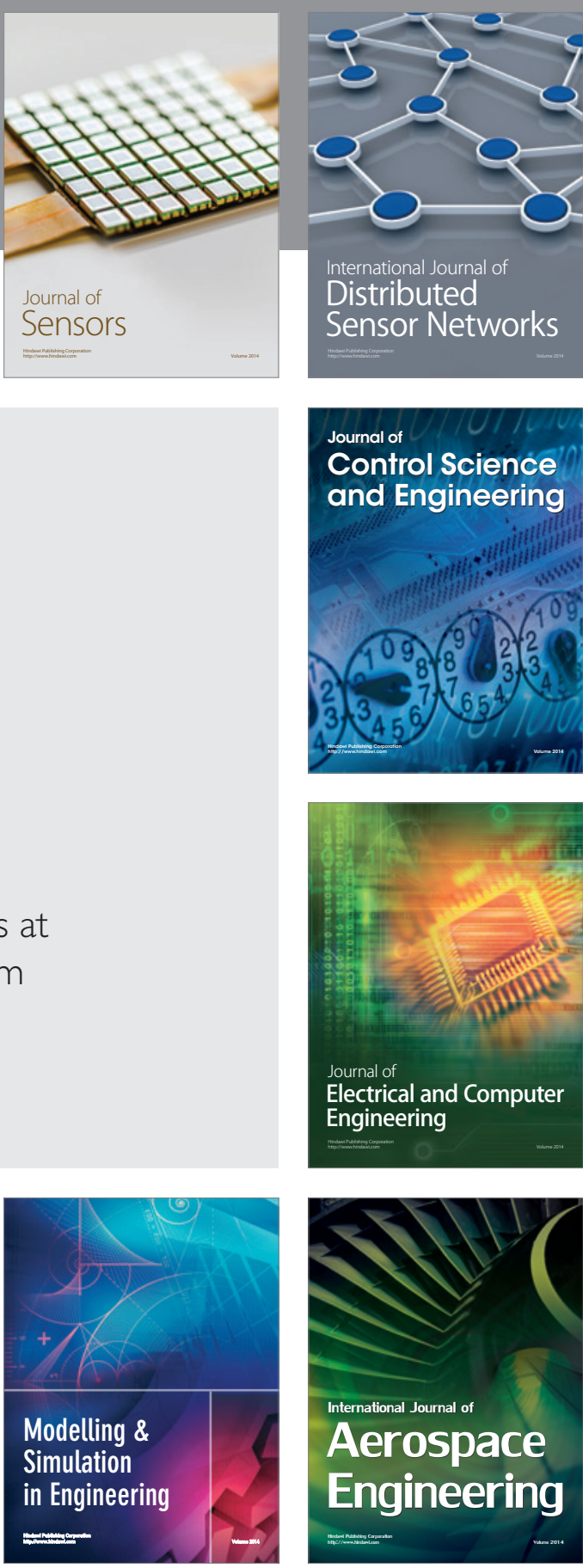

International Journal of

Distributed

Sensor Networks

Journal of

Control Science

and Engineering
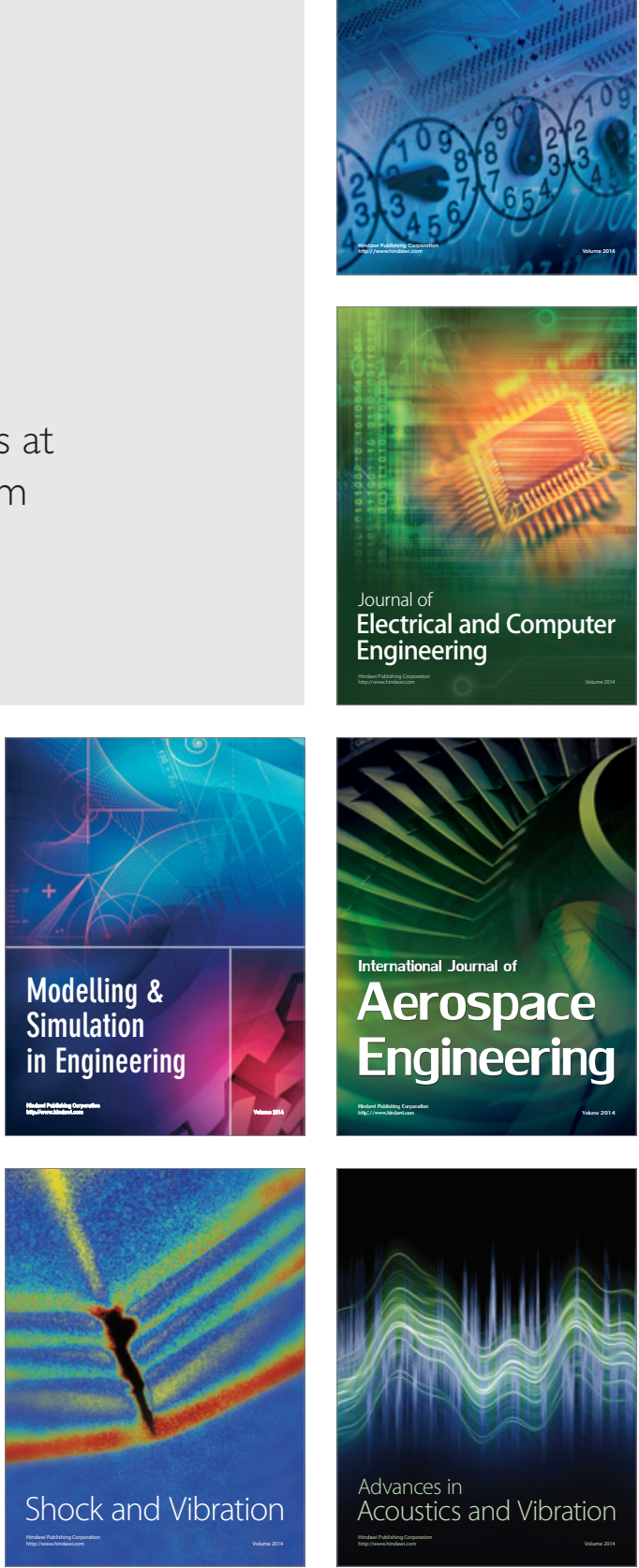